\title{
Solubility of Anthracene in Ternary Solvent Mixtures of 2,2,4-Trimethylpentane + 2-Propanone + Alcohols at 298.15 K
}

\author{
Ali Shayanfar, ${ }^{\dagger}$ Somaieh Soltani, ${ }^{\ddagger}$ Farnaz Jabbaribar, ${ }^{\S}$ Elnaz Tamizi, ${ }^{\prime \prime}$ William E. Acree, Jr., ${ }^{\perp}$ and \\ Abolghasem Jouyban*,\#
}

Student Research Center, Pharmaceutical Nanotechnology Research Center, Drug Applied Research Center, and Biotechnology Research Center, Tabriz University of Medical Sciences, Tabriz 51664, Iran, Department of Chemistry, University of North Texas, Denton, Texas 76203-5070, and Kimia Research Institute, Tabriz, Iran

\begin{abstract}
Experimental solubilities are reported for anthracene dissolved in ternary solvent mixtures of 2,2,4trimethylpentane + 2-propanone + methanol, 2,2,4-trimethylpentane + 2-propanone + ethanol, 2,2,4trimethylpentane + 2-propanone +1 -propanol, and 2,2,4-trimethylpentane +2 -propanone +2 -propanol at 298.15 K. Nineteen compositions are studied for each of the four solvent systems. Results of these measurements were used to evaluate the prediction capability of a previously developed quantitative structure-property relationship employing the experimental solubility data in monosolvents, and the overall mean deviation (OMD) of the models varied between (13.5 and 15.5) \%. Using fully predictive methods, the OMDs varied between (13.1 and 18.2) \%.
\end{abstract}

\section{Introduction}

Solubility data are essential information for crystallizationbased separations and chromatographic resolutions and also designing new drug formulations. Mixing solvents is a common method to alter the solubility. However, there is a significant lack of solubility data for many solutes; therefore, efforts have been devoted to obtain the required information with a minimum time and substance consumption. When the binary solvent mixtures are not able to dissolve a desired amount of a solute in a given volume, the third solvent could be added to the mixture. The possible number of compositions for the ternary solvents is quite high, and all of them could not be determined experimentally. The development of the ab initio solubility prediction methods with an acceptable error range would be an ideal solution to address the problem. A number of mathematical models have been presented for this purpose, and a summary of the models was given in a recent paper. ${ }^{1}$

Experimental solubility data of anthracene in a number of ternary solvent mixtures have been reported by Acree and coworkers, and their references were listed in a previous work. ${ }^{2}$ However, there were no published data on the solubility of anthracene in 2,2,4-trimethylpentane +2 -propanone + alcohol mixtures. 2,2,4-Trimethylpentane is a highly branched saturated hydrocarbon and has been used in several partitioning studies to model the oil phase ${ }^{3-5}$ and was also used as a reference solvent in solubility studies involving drug molecules. ${ }^{6}$

A numerical method was developed employing the JouybanAcree model, the Abraham solute parameters, and the Abraham solvent coefficients. ${ }^{7}$ The basic Jouyban-Acree model for calculating the solubility of solutes in ternary solvents is

\footnotetext{
* Author to whom correspondence should be addressed. E-mail: ajouyban@ hotmail.com. Fax: +98 4113363231 .

${ }^{\dagger}$ Student Research Center.

Pharmaceutical Nanotechnology Research Center.

$\S$ Drug Applied Research Center.

"Biotechnology Research Center.

${ }^{\perp}$ University of North Texas.

\# Kimia Research Institute.
}

$$
\begin{aligned}
\ln C_{m}^{\mathrm{Sat}}= & x_{1} \ln C_{1}^{\mathrm{Sat}}+x_{2} \ln C_{2}^{\mathrm{Sat}}+x_{3} \ln C_{3}^{\mathrm{Sat}}+ \\
& x_{1} x_{2} \sum_{i=0}^{2} J_{i}\left(x_{1}-x_{2}\right)^{i}+x_{1} x_{3} \sum_{i=0}^{2} J_{i}\left(x_{1}-x_{3}\right)^{i}+ \\
& x_{2} x_{3} \sum_{i=0}^{2} J_{i}^{\prime \prime}\left(x_{2}-x_{3}\right)^{i}
\end{aligned}
$$

where $C_{m}^{\mathrm{Sat}}$ is the solute $\mathrm{mol} \cdot \mathrm{L}^{-1}$ solubility in the ternary solvent mixtures; $x_{1}, x_{2}$, and $x_{3}$ are the mole fractions of solvents 1,2 , and 3 in the absence of the solute; $C_{1}^{\mathrm{Sat}}, C_{2}^{\mathrm{Sat}}$, and $C_{3}^{\mathrm{Sat}}$ denote the $\mathrm{mol} \cdot \mathrm{L}^{-1}$ solubility of the solute in the neat solvents 1,2 , and 3 , respectively; and $J_{i}$ (for binary mixtures of solvents 1 and 2 ), $j_{i}{ }^{\prime}$ (for binary mixtures of solvents 1 and 3 ), and $j_{\mathrm{i}}^{\prime \prime}$ (for binary mixtures of solvents 2 and 3 ) are the curve-fit coefficients in the Jouyban-Acree model that are determined through regressional analysis by fitting the measured anthracene solubilities in the respective binary solvents to eq 1 . The solution model used in deriving eq 1 is based on two-body and three-body interactions, and the various curve-fit coefficients are functions of solvent-solvent and solute-solvent interaction terms. The coefficients are described in greater detail elsewhere. ${ }^{8}$ It should be noted that all $C^{\text {Sat }}$ terms in this work are expressed as the number of moles of anthracene dissolved in a liter of the solution. In a previous work, ${ }^{7}$ quantitative structure-property relationships (QSPRs) were proposed to calculate the numerical values of the $J_{i}, J_{i}^{\prime}$, and $J_{i}^{\prime \prime}$ terms using Abraham solvent coefficients of 22 solvents and Abraham parameters of five solutes. The QSPRs enable us to predict the solubility of a solute in nonaqueous mixed solvent without employing any experimental data from mixed solvents.

The QSPR models proposed in an earlier work ${ }^{7}$ using waterto-solvent coefficients were

$$
\begin{aligned}
& J_{0}=0.028+2.123\left(c_{1}-c_{2}\right)^{2}-0.160 E\left(e_{1}-e_{2}\right)^{2}+ \\
& \quad 0.282 S\left(s_{1}-s_{2}\right)^{2}+1.713 B\left(b_{1}-b_{2}\right)^{2}+2.006 V\left(v_{1}-v_{2}\right)^{2}(2) \\
& J_{1}=0.033+0.670\left(c_{1}-c_{2}\right)^{2}-0.477 E\left(e_{1}-e_{2}\right)^{2}+ \\
& 0.051 S\left(s_{1}-s_{2}\right)^{2}+0.476 B\left(b_{1}-b_{2}\right)^{2}-0.234 V\left(v_{1}-v_{2}\right)^{2}(3)
\end{aligned}
$$


$J_{2}=0.022+2.024\left(c_{1}-c_{2}\right)^{2}-0.204 E\left(e_{1}-e_{2}\right)^{2}+$ $0.034 S\left(s_{1}-s_{2}\right)^{2}+0.243 B\left(b_{1}-b_{2}\right)^{2}+0.848 V\left(v_{1}-v_{2}\right)^{2}$

and the QSPR models using gas-to-solvent coefficients were

$$
\begin{aligned}
& J_{0}=0.062+0.118\left(c_{1}-c_{2}\right)^{2}-0.332 E\left(e_{1}-e_{2}\right)^{2}+ \\
& 0.410 S\left(s_{1}-s_{2}\right)^{2}+2.399 B\left(b_{1}-b_{2}\right)^{2}+15.715 L\left(l_{1}-l_{2}\right)^{2} \\
& J_{1}=0.103-1.864\left(c_{1}-c_{2}\right)^{2}-1.590 E\left(e_{1}-e_{2}\right)^{2}+ \\
& 0.119 S\left(s_{1}-s_{2}\right)^{2}+1.010 B\left(b_{1}-b_{2}\right)^{2}-9.493 L\left(l_{1}-l_{2}\right)^{2} \\
& J_{2}=-0.008+1.075\left(c_{1}-c_{2}\right)^{2}+0.053 E\left(r_{1}-r_{2}\right)^{2}+ \\
& 0.084 S\left(s_{1}-s_{2}\right)^{2}+0.414 B\left(b_{1}-b_{2}\right)^{2}+7.727 L\left(l_{1}-l_{2}\right)^{2}
\end{aligned}
$$

where $c, e, s, b, v$, and $l$ are the model constants (i.e., the Abraham solvent coefficients); subscripts 1 and 2 denote solvents 1 and 2; $E$ is the excess molar refraction of solute; $S$ is dipolarity/polarizability of solute; $B$ stands for the solute's hydrogen-bond basicity; $V$ is the McGowan volume of the solute; and $L$ is the logarithm of the solute gas-hexadecane partition coefficient at $298.15 \mathrm{~K}$. The numerical values of $c, e$, $s, b, v$, and $l$ employed in this work were listed in Table 1 . The numerical values of the $j_{i}^{\prime}$ and $j_{i}^{\prime \prime}$ terms were also computed using eqs 2 to 4 (water-to-solvent) and eqs 5 to 7 (gas-to-solvent) employing the corresponding Abraham solvent coefficients.

The aims of this work are to report the experimental solubility data of anthracene in ternary mixtures of 2,2,4-trimethylpentane, 2-propanone, and $\mathrm{C}_{1}-\mathrm{C}_{3}$ alcohol at $298.15 \mathrm{~K}$ and also to check the prediction capability of previously reported QSPR models for predicting the solubility of solutes in ternary solvent mixtures.

\section{Experimental Method}

Materials. Anthracene (purity $96 \%$ ) was purchased from Fluka, and it was recrystallized several times from 2-propanone and ethyl acetate to yield a purified sample having a melting point of $488 \mathrm{~K}$. The purity of recrystallized anthracene ( $\sim 99$ $\%$ ) was checked by IR spectroscopy, and also the measured solubilities in a number of monosolvents were compared with the corresponding data from the literature. 2,2,4-Trimethylpentane (>99 \%), 1-propanol (99.5\%), 2-propanol (99.5\%), absolute ethanol (99.9\%), and methanol $(99.5 \%)$ were purchased from Merck.

Apparatus and Procedure. The ternary solvent mixtures were prepared by mixing the appropriate volumes of the solvents, and then the mole fractions of the solvents were computed considering the densities of the neat solvents. The solvent composition could be calculated to $0.005 \mathrm{~mol}$ fractions. The solubility of anthracene was determined by equilibrating an excess amount of the solid with the ternary solvent mixtures at 298.15 K using a shaker (Behdad, Tehran, Iran) placed in an incubator equipped with a temperature controlling system with $\pm 0.2 \mathrm{~K}$. Attainment of the equilibrium was verified by solubility measurements at different times and reached after $72 \mathrm{~h}$. The solutions were filtered using hydrophobic Durapore filters ( 0.45 $\mu \mathrm{m}$, Millipore, Ireland) and then diluted with methanol for spectrophotometric analysis at $356 \mathrm{~nm}$ quantified by a UV-vis spectrophotometer (Beckman DU-650, Fullerton, USA). The filter did not absorb the solute through a filtration process. Concentrations of the dilute solutions were determined from a UV absorbance calibration graph with the molar concentration of anthracene ranging from $\epsilon /\left(\mathrm{L} \cdot \mathrm{mol}^{-1} \cdot \mathrm{cm}^{-1}\right)=6947$ to $\epsilon /\left(\mathrm{L} \cdot \mathrm{mol}^{-1} \cdot \mathrm{cm}^{-1}\right)=6645$ for the anthracene compositions ranging from $\left(3.31 \cdot 10^{-5}\right.$ to $\left.2.65 \cdot 10^{-4}\right) \mathrm{mol} \cdot \mathrm{L}^{-1}$. Each experi-
Table 1. Abraham Solvent Coefficients Employed in This Work Taken from Reference 10

\begin{tabular}{lrccrrc}
\hline \multicolumn{1}{c}{ water to solvent } & $c$ & $e$ & $s$ & \multicolumn{1}{c}{$a$} & $b$ & $v$ \\
\hline 1-propanol & 0.148 & 0.436 & -1.098 & 0.389 & -3.893 & 4.036 \\
2,2,4-trimethylpentane & 0.288 & 0.382 & -1.668 & -3.639 & -5.000 & 4.461 \\
2-propanol & 0.063 & 0.320 & -1.024 & 0.445 & -3.824 & 4.067 \\
2-propanone & 0.335 & 0.349 & -0.231 & -0.411 & -4.796 & 3.963 \\
ethanol & 0.208 & 0.409 & -0.959 & 0.186 & -3.645 & 3.928 \\
methanol & 0.329 & 0.299 & -0.671 & 0.080 & -3.389 & 3.512 \\
\hline \multicolumn{1}{c}{ gas to solvent } & \multicolumn{1}{c}{$c$} & $e$ & $s$ & $a$ & $b$ & $l$ \\
\hline 1-propanol & -0.028 & -0.185 & 0.648 & 4.022 & 1.043 & 0.869 \\
2,2,4-trimethylpentane & 0.275 & -0.244 & 0.000 & 0.000 & 0.000 & 0.972 \\
2-propanol & -0.060 & -0.335 & 0.702 & 4.017 & 1.040 & 0.893 \\
2-propanone & 0.154 & -0.277 & 1.522 & 3.258 & 0.078 & 0.863 \\
ethanol & 0.012 & -0.206 & 0.789 & 3.635 & 1.311 & 0.853 \\
methanol & -0.004 & -0.215 & 1.173 & 3.701 & 1.432 & 0.769
\end{tabular}

mental data point is an average of at least three experiments with the measured $\mathrm{mol} \cdot \mathrm{L}^{-1}$ solubilities being reproducible to within $\pm 2.0 \%$. Calculated standard deviations ranged from $\sigma_{n}-1=0.0002$ to $\sigma_{n}-1=0.0018 \mathrm{~mol} \cdot \mathrm{L}^{-1}$.

Computational Methods. The $J_{i}, j_{i}^{\prime}$, and $j_{i}^{\prime \prime}$ terms of the Jouyban-Acree model were computed using eqs 2 to 4 and then were used to predict anthracene solubility data in ternary solvent mixtures using eq 1 employing experimental values of

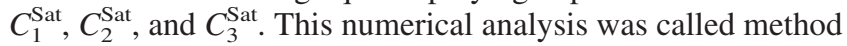
I. The same computations were carried out employing eqs 5 to 7 , and it was called numerical method II. For solubility prediction methods I and II, the solubility data in monosolvent systems, i.e., three points for each ternary solvent system, are required. To further reduce the experimental data requirement in the prediction process, it is possible to use the Abraham solvation models to predict $C_{1}^{\text {Sat }}, C_{2}^{\text {Sat }}$, and $C_{3}^{\text {Sat }}$ values and use the predicted solubilities in monosolvents in eq 1. The Abraham model for the water-to-solvent process is

$$
\log \left(\frac{C_{\mathrm{S}}}{C_{\mathrm{W}}}\right)=c+e \cdot E+s \cdot S+a \cdot A+b \cdot B+v \cdot V
$$

and for the gas-to-solvent process

$$
\log \left(\frac{C_{\mathrm{S}}}{C_{\mathrm{G}}}\right)=c+e \cdot E+s \cdot S+a \cdot A+b \cdot B+l \cdot L
$$

where $C_{\mathrm{S}}$ (the same term as $C_{1}^{\mathrm{Sat}}, C_{2}^{\mathrm{Sat}}$, and $C_{3}^{\mathrm{Sat}}$ from this work) and $C_{\mathrm{W}}$ are the solute solubility in the organic solvent and water (in $\mathrm{mol} \cdot \mathrm{L}^{-1}$ ), respectively; $a$ is the Abraham solvent coefficient; $A$ denotes the solute's hydrogen-bond acidity; and $C_{\mathrm{G}}$ is the gas phase concentration of the solute. Equation 8 requires the aqueous solubility of the solute $\left(C_{\mathrm{W}}\right)$, and eq 9 requires the $C_{\mathrm{G}}$ value. The numerical values of the solute's Abraham experimental parameters for anthracene are: $\log C_{\mathrm{W}}=-6.430, E=$ 2.290, $S=1.340, A=0.000, B=0.280, V=1.454, L=7.568$, and $\log C_{\mathrm{G}}=-9.460$. $^{9}$ The predicted $C_{1}^{\mathrm{Sat}}, C_{2}^{\mathrm{Sat}}$, and $C_{3}^{\text {Sat }}$ from eq 8 and $J$ terms computed using eqs 2 to 4 were used to predict the $C_{m}^{\text {Sat }}$, and this numerical method was called method III. A similar numerical analysis employing eqs 9 and 5 to 7 was called method IV.

All predicted solubilities $\left(C_{m}^{\text {Sat }}\right)$ were compared with the corresponding experimental values, and the mean deviation (MD) was calculated as a criterion by eq 10

$$
\mathrm{MD}=\frac{\sum\left\{\frac{\mathrm{l}\left(C_{m}^{\mathrm{Sat}}\right)_{\mathrm{pred}}-\left(C_{m}^{\mathrm{Sat}}\right) \mid}{\left(C_{m}^{\mathrm{Sat}}\right)}\right\}}{N}
$$

where $N$ is the number of data points in each set. 
Table 2. Experimental Solubilities of Anthracene in Ternary Mixtures of 2,2,4-Trimethylpentane ( $\left.x_{1}\right)$, 2-Propanone ( $\left.x_{2}\right)$, and the Aliphatic Alcohols $\left(x_{3}\right)$ at $298.15 \mathrm{~K}$, Density $(\rho)$ of the Saturated Solutions, and the Computed Solubilities Using Equation 1 and Various Numerical Analyses $^{a}$

\begin{tabular}{|c|c|c|c|c|c|c|c|c|c|c|c|c|c|c|c|}
\hline \multirow{2}{*}{ 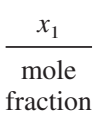 } & \multirow{2}{*}{ 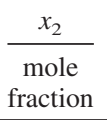 } & \multirow{2}{*}{$\frac{C_{m}^{\mathrm{Sat}}}{\mathrm{mol} \cdot \mathrm{L}^{-1}}$} & \multirow{2}{*}{$\frac{\rho}{\mathrm{g} \cdot \mathrm{cm}^{-3}}$} & \multicolumn{4}{|c|}{$C_{m}^{\mathrm{Sat}} / \mathrm{mol} \cdot \mathrm{L}^{-1}$} & \multirow{2}{*}{ 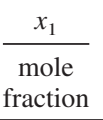 } & \multirow{2}{*}{ 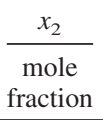 } & \multirow{2}{*}{$\frac{C_{m}^{\mathrm{Sat}}}{\mathrm{mol} \cdot \mathrm{L}^{-1}}$} & \multirow{2}{*}{$\frac{\rho}{\mathrm{g} \cdot \mathrm{cm}^{-3}}$} & \multicolumn{4}{|c|}{$C_{m}^{\mathrm{Sat}} / \mathrm{mol} \cdot \mathrm{L}^{-1}$} \\
\hline & & & & $\begin{array}{c}\text { method } \\
\text { I }\end{array}$ & $\begin{array}{c}\text { method } \\
\text { II }\end{array}$ & $\begin{array}{c}\text { method } \\
\text { III }\end{array}$ & $\begin{array}{c}\text { method } \\
\text { IV }\end{array}$ & & & & & $\begin{array}{c}\text { method } \\
\text { I }\end{array}$ & $\begin{array}{c}\text { method } \\
\text { II }\end{array}$ & $\begin{array}{c}\text { method } \\
\text { III }\end{array}$ & $\begin{array}{l}\text { method } \\
\text { IV }\end{array}$ \\
\hline \multicolumn{16}{|c|}{ 1-propanol $\left(\mathrm{MV}=0.07510 \mathrm{~L} \cdot \mathrm{mol}^{-1}\right)$} \\
\hline 0.513 & 0.165 & 0.016 & 0.721 & 0.015 & 0.014 & 0.013 & 0.012 & 0.102 & 0.114 & 0.014 & 0.779 & 0.012 & 0.012 & 0.015 & 0.014 \\
\hline 0.511 & 0.328 & 0.019 & 0.712 & 0.020 & 0.018 & 0.018 & 0.016 & 0.101 & 0.342 & 0.028 & 0.771 & 0.019 & 0.019 & 0.024 & 0.023 \\
\hline 0.454 & 0.315 & 0.021 & 0.717 & 0.019 & 0.018 & 0.018 & 0.017 & 0.100 & 0.789 & 0.040 & 0.767 & 0.037 & 0.035 & 0.052 & 0.049 \\
\hline 0.311 & 0.140 & 0.017 & 0.742 & 0.014 & 0.013 & 0.014 & 0.013 & 0.074 & 0.166 & 0.017 & 0.781 & 0.013 & 0.013 & 0.017 & 0.016 \\
\hline 0.309 & 0.418 & 0.026 & 0.735 & 0.023 & 0.021 & 0.025 & 0.023 & 0.073 & 0.766 & 0.040 & 0.773 & 0.036 & 0.034 & 0.050 & 0.049 \\
\hline 0.309 & 0.556 & 0.028 & 0.731 & 0.029 & 0.026 & 0.032 & 0.029 & 0.048 & 0.428 & 0.030 & 0.781 & 0.021 & 0.021 & 0.029 & 0.028 \\
\hline 0.232 & 0.130 & 0.017 & 0.748 & 0.013 & 0.013 & 0.015 & 0.014 & 0.047 & 0.534 & 0.033 & 0.783 & 0.025 & 0.025 & 0.035 & 0.034 \\
\hline 0.229 & 0.645 & 0.036 & 0.742 & 0.032 & 0.030 & 0.039 & 0.036 & 0.048 & 0.269 & 0.023 & 0.783 & 0.016 & 0.016 & 0.021 & 0.021 \\
\hline 0.161 & 0.484 & 0.031 & 0.760 & 0.025 & 0.024 & 0.031 & 0.029 & 0.047 & 0.745 & 0.043 & 0.785 & 0.034 & 0.033 & 0.049 & 0.048 \\
\hline 0.130 & 0.584 & 0.034 & 0.765 & 0.029 & 0.027 & 0.037 & 0.035 & & & & & & & & \\
\hline \multicolumn{16}{|c|}{ 2-propanol $\left(\mathrm{MV}=0.07690 \mathrm{~L} \cdot \mathrm{mol}^{-1}\right)$} \\
\hline 0.516 & 0.166 & 0.014 & 0.717 & 0.013 & 0.012 & 0.011 & 0.010 & 0.103 & 0.116 & 0.012 & 0.752 & 0.009 & 0.009 & 0.011 & 0.010 \\
\hline 0.512 & 0.329 & 0.019 & 0.715 & 0.019 & 0.017 & 0.017 & 0.015 & 0.102 & 0.345 & 0.020 & 0.763 & 0.016 & 0.015 & 0.020 & 0.019 \\
\hline 0.456 & 0.316 & 0.018 & 0.721 & 0.018 & 0.016 & 0.017 & 0.015 & 0.100 & 0.791 & 0.040 & 0.765 & 0.036 & 0.034 & 0.050 & 0.047 \\
\hline 0.314 & 0.141 & 0.012 & 0.737 & 0.012 & 0.011 & 0.012 & 0.011 & 0.075 & 0.169 & 0.014 & 0.766 & 0.010 & 0.010 & 0.012 & 0.012 \\
\hline 0.311 & 0.420 & 0.024 & 0.735 & 0.021 & 0.019 & 0.023 & 0.021 & 0.073 & 0.768 & 0.039 & 0.767 & 0.034 & 0.033 & 0.048 & 0.046 \\
\hline 0.309 & 0.557 & 0.031 & 0.736 & 0.028 & 0.025 & 0.031 & 0.028 & 0.048 & 0.432 & 0.025 & 0.771 & 0.018 & 0.018 & 0.024 & 0.023 \\
\hline 0.234 & 0.132 & 0.013 & 0.740 & 0.011 & 0.010 & 0.011 & 0.011 & 0.048 & 0.538 & 0.029 & 0.773 & 0.022 & 0.022 & 0.030 & 0.029 \\
\hline 0.230 & 0.646 & 0.034 & 0.744 & 0.031 & 0.028 & 0.038 & 0.034 & 0.048 & 0.272 & 0.014 & 0.783 & 0.013 & 0.013 & 0.016 & 0.016 \\
\hline 0.162 & 0.487 & 0.027 & 0.756 & 0.022 & 0.021 & 0.027 & 0.025 & 0.047 & 0.747 & 0.037 & 0.779 & 0.035 & 0.034 & 0.046 & 0.044 \\
\hline 0.130 & 0.587 & 0.031 & 0.752 & 0.026 & 0.025 & 0.034 & 0.032 & & & & & & & & \\
\hline \multicolumn{16}{|c|}{ ethanol $\left(\mathrm{MV}=0.05870 \mathrm{~L} \cdot \mathrm{mol}^{-1}\right)$} \\
\hline 0.465 & 0.150 & 0.014 & 0.717 & 0.016 & 0.015 & 0.016 & 0.014 & 0.081 & 0.092 & 0.014 & 0.769 & 0.013 & 0.012 & 0.018 & 0.017 \\
\hline 0.486 & 0.313 & 0.019 & 0.712 & 0.021 & 0.019 & 0.020 & 0.018 & 0.086 & 0.290 & 0.022 & 0.765 & 0.019 & 0.018 & 0.026 & 0.026 \\
\hline 0.423 & 0.293 & 0.020 & 0.721 & 0.021 & 0.019 & 0.021 & 0.019 & 0.097 & 0.763 & 0.038 & 0.767 & 0.037 & 0.035 & 0.052 & 0.050 \\
\hline 0.265 & 0.119 & 0.014 & 0.735 & 0.015 & 0.014 & 0.018 & 0.016 & 0.060 & 0.134 & 0.016 & 0.773 & 0.013 & 0.013 & 0.019 & 0.019 \\
\hline 0.285 & 0.385 & 0.023 & 0.733 & 0.024 & 0.022 & 0.028 & 0.026 & 0.069 & 0.729 & 0.035 & 0.773 & 0.035 & 0.034 & 0.051 & 0.049 \\
\hline 0.296 & 0.533 & 0.030 & 0.735 & 0.029 & 0.026 & 0.033 & 0.031 & 0.041 & 0.367 & 0.025 & 0.779 & 0.021 & 0.021 & 0.030 & 0.030 \\
\hline 0.193 & 0.108 & 0.016 & 0.746 & 0.014 & 0.013 & 0.018 & 0.017 & 0.042 & 0.472 & 0.029 & 0.777 & 0.024 & 0.024 & 0.036 & 0.036 \\
\hline 0.220 & 0.620 & 0.034 & 0.742 & 0.032 & 0.030 & 0.040 & 0.037 & 0.039 & 0.221 & 0.020 & 0.781 & 0.016 & 0.016 & 0.023 & 0.023 \\
\hline 0.145 & 0.435 & 0.027 & 0.756 & 0.025 & 0.024 & 0.033 & 0.031 & 0.044 & 0.698 & 0.036 & 0.781 & 0.039 & 0.034 & 0.049 & 0.043 \\
\hline 0.119 & 0.536 & 0.031 & 0.760 & 0.028 & 0.027 & 0.039 & 0.037 & & & & & & & & \\
\hline \multicolumn{16}{|c|}{ methanol $\left(\mathrm{MV}=0.04070 \mathrm{~L} \cdot \mathrm{mol}^{-1}\right)$} \\
\hline 0.402 & 0.129 & 0.014 & 0.712 & 0.022 & 0.014 & 0.020 & 0.013 & 0.061 & 0.069 & 0.013 & 0.767 & 0.010 & 0.008 & 0.012 & 0.010 \\
\hline 0.449 & 0.289 & 0.019 & 0.713 & 0.026 & 0.019 & 0.024 & 0.017 & 0.069 & 0.232 & 0.016 & 0.765 & 0.016 & 0.013 & 0.020 & 0.016 \\
\hline 0.380 & 0.263 & 0.018 & 0.715 & 0.025 & 0.018 & 0.025 & 0.017 & 0.092 & 0.722 & 0.033 & 0.771 & 0.038 & 0.032 & 0.051 & 0.044 \\
\hline 0.212 & 0.095 & 0.014 & 0.733 & 0.017 & 0.011 & 0.017 & 0.012 & 0.045 & 0.101 & 0.011 & 0.773 & 0.010 & 0.009 & 0.012 & 0.011 \\
\hline 0.251 & 0.339 & 0.022 & 0.733 & 0.027 & 0.019 & 0.029 & 0.021 & 0.064 & 0.674 & 0.033 & 0.775 & 0.035 & 0.030 & 0.048 & 0.041 \\
\hline 0.277 & 0.498 & 0.028 & 0.733 & 0.032 & 0.025 & 0.036 & 0.028 & 0.033 & 0.296 & 0.019 & 0.781 & 0.017 & 0.015 & 0.022 & 0.018 \\
\hline 0.150 & 0.084 & 0.013 & 0.744 & 0.014 & 0.010 & 0.015 & 0.011 & 0.035 & 0.394 & 0.022 & 0.781 & 0.021 & 0.018 & 0.027 & 0.023 \\
\hline 0.207 & 0.582 & 0.029 & 0.744 & 0.034 & 0.028 & 0.041 & 0.033 & 0.030 & 0.170 & 0.013 & 0.783 & 0.012 & 0.011 & 0.015 & 0.013 \\
\hline 0.124 & 0.371 & 0.024 & 0.760 & 0.024 & 0.019 & 0.029 & 0.023 & 0.040 & 0.632 & 0.028 & 0.781 & 0.032 & 0.028 & 0.044 & 0.038 \\
\hline 0.104 & 0.470 & 0.027 & 0.763 & 0.028 & 0.022 & 0.035 & 0.028 & & & & & & & & \\
\hline
\end{tabular}

${ }^{a}$ I: Experimental $C_{1}^{\text {Sat }}, C_{2}^{\text {Sat }}$, and $C_{3}^{\text {Sat }}$ and computed $J\left(J_{i}, j_{i}^{\prime}\right.$ and $\left.j_{i}{ }^{\prime \prime}\right)$ terms using eqs 2 to 4 . II: Experimental $C_{1}^{\text {Sat }}, C_{2}^{\text {Sat }}$, and $C_{3}^{\text {Sat }}$ and computed $J$ terms using eqs 5 to 7. III: Predicted $C_{1}^{\text {Sat }}, C_{2}^{\text {Sat }}$, and $C_{3}^{\text {Sat }}$ using eq 8 and computed $J$ terms using eqs 2 to 4 . III: Predicted $C_{1}^{\text {Sat }}, C_{2}^{\text {Sat }}$, and $C_{3}^{\text {Sat }}$ using eq 9 and computed $J$ terms using eqs 5 to 7.

\section{Results and Discussion}

Table 2 lists the experimental solubility of anthracene in ternary solvent mixtures. Each experimental data point is an average of at least three experiments, and the uncertainty of the data was $\pm 3.3 \%$. There are good agreements between the reported solubility of anthracene in methanol $\left(0.00597 \mathrm{~mol} \cdot \mathrm{L}^{-1}\right)$, 1-propanol $\left(0.00787 \mathrm{~mol} \cdot \mathrm{L}^{-1}\right)$, 2-propanol $\left(0.00534 \mathrm{~mol} \cdot \mathrm{L}^{-1}\right)$, 2-propanone $\left(0.05180 \mathrm{~mol} \cdot \mathrm{L}^{-1}\right)$, ethanol $\left(0.007784 \mathrm{~mol} \cdot \mathrm{L}^{-1}\right)$, and 2,2,4-trimethylpentane $\left(0.00655 \mathrm{~mol} \cdot \mathrm{L}^{-1}\right)$ from the literature ${ }^{9}$ and the determined solubilities for methanol $\left(0.00580 \mathrm{~mol} \cdot \mathrm{L}^{-1}\right)$, 1-propanol $\left(0.00822 \mathrm{~mol} \cdot \mathrm{L}^{-1}\right)$, 2-propanol $\left(0.00571 \mathrm{~mol} \cdot \mathrm{L}^{-1}\right)$, 2-propanone $\left(0.04353 \mathrm{~mol} \cdot \mathrm{L}^{-1}\right)$, ethanol $\left(0.00868 \mathrm{~mol} \cdot \mathrm{L}^{-1}\right)$, and 2,2,4-trimethylpentane $\left(0.00669 \mathrm{~mol} \cdot \mathrm{L}^{-1}\right)$ in this work. The solubility of anthracene in ternary solvents was predicted using numerical methods I to IV. The predicted solubilities were compared with the corresponding experimental data, and the MD values were computed. The MD values of various numerical
Table 3. Numerical Values of the Mean Deviation (MD) for the Predicted Solubilities of Anthracene in 2,2,4-Trimethylpentane (1) + 2-Propanone (2) + Alcohols (3) Using Various Numerical Methods and Their Overall Values

\begin{tabular}{|c|c|c|c|c|}
\hline & \multicolumn{4}{|c|}{ numerical method } \\
\hline & I & II & III & IV \\
\hline solvent 3 & \multicolumn{4}{|c|}{$100 \cdot \mathrm{MD}$ (using eq 1 ) } \\
\hline 1-propanol & 16.1 & 20.2 & 11.5 & 12.0 \\
\hline 2-propanol & 12.3 & 18.4 & 10.6 & 12.4 \\
\hline ethanol & 9.8 & 10.4 & 21.2 & 16.1 \\
\hline methanol & 15.7 & 13.1 & 29.7 & 11.8 \\
\hline overall MD \%: & 13.5 & 15.5 & 18.2 & 13.1 \\
\hline solvent 3 & \multicolumn{4}{|c|}{$100 \cdot \mathrm{MD}$ (using eq 11$)$} \\
\hline 1-propanol & 20.0 & 24.0 & 12.6 & 14.2 \\
\hline 2-propanol & 16.4 & 22.2 & 12.1 & 15.1 \\
\hline ethanol & 11.6 & 16.0 & 14.3 & 13.1 \\
\hline methanol & 10.7 & 22.2 & 17.0 & 16.8 \\
\hline overall MD \%: & 14.7 & 21.2 & 14.0 & 14.9 \\
\hline
\end{tabular}


methods and their overall MD were listed in Table 3. Of the numerical methods employing the experimental solubilities in solvents 1,2 , and 3 , the method I was the best prediction method, whereas the numerical method IV was the best fully predictive method for anthracene solubilities in the investigated solvent systems. These findings are in agreement with the previous results obtained for the same analyses employing 194 data sets. ${ }^{7}$

Equations 2 to 7 were trained using the solubility data sets expressed in mole fraction units; however, in this work, we expressed the solubilities in $\mathrm{mol} \cdot \mathrm{L}^{-1}$, and this difference in solubility expression could be compensated by adding a correction term to the Jouyban-Acree model as

$$
\begin{gathered}
\ln C_{m}^{\mathrm{Sat}}=x_{1} \ln C_{1}^{\mathrm{Sat}}+x_{2} \ln C_{2}^{\mathrm{Sat}}+x_{3} \ln C_{3}^{\mathrm{Sat}}+ \\
x_{1} x_{2} \sum_{i=0}^{2} J_{i}\left(x_{1}-x_{2}\right)^{i}+x_{1} x_{3} \sum_{i=0}^{2} J_{i}^{\prime}\left(x_{1}-x_{3}\right)^{i}+x_{2} x_{3} \sum_{i=0}^{2} J_{i}^{\prime \prime}\left(x_{2}-\right. \\
\left.x_{3}\right)^{i}+\left[x_{1} \ln \mathrm{MV}_{1}+x_{2} \ln \mathrm{MV}_{2}+x_{3} \ln \mathrm{MV}_{3}-\right. \\
\left.\ln \left(x_{1} \mathrm{MV}_{1}+x_{2} \mathrm{MV}_{2}+x_{3} \mathrm{MV}_{3}\right)\right]
\end{gathered}
$$

in which $\mathrm{MV}_{1}-, \mathrm{MV}_{2}$, and $\mathrm{MV}_{3}$ are the molar volumes of the solvents 1, 2, and 3, respectively. The numerical values of MV for the solvents used in this work are reported in Table 2. This correction improves the MD of the proposed method, as a detailed report could be found in Table 3 .

Generally the overall MDs observed in these computations reveal that the developed QSPR models are robust and could be used for prediction purposes.

\section{Literature Cited}

(1) Jouyban, A.; Chew, N. Y. K.; Chan, H. K.; Sabour, M.; Acree, W. E., Jr. A Unified Cosolvency Model for Calculating Solute Solubility in Mixed Solvents. Chem. Pharm. Bull. 2005, 53, 634-637.
(2) Jouyban, A.; Chan, H. K.; Khoub nasabjafari, M.; Clark, B. J.; Acree, W. E., Jr. Solubility Prediction of Anthracene in Mixed Solvents Using a Minimum Number of Experimental Data. Chem. Pharm. Bull. 2002, $50,21-25$.

(3) Standal, S. H.; Blokhus, A. M.; Haavik, J.; Skauge, A.; Barth, T. Partition Coefficients and Interfacial Activity for Polar Components in Oil/Water Model Systems. J. Colloid Interface Sci. 1999, 212, 33 41.

(4) Fujiwara, H.; Da, Y. Z.; Ito, K.; Takagi, T.; Nishioka, Y. The Energy Aspect of Oil-Water Partition and its Application to the Analysis of Quantitative Structure-Activity Relationships. Aliphatic Alcohols in the Liposome-Water Partition System. Bull. Chem. Soc. Jpn. 1991, 64, 3707-3712.

(5) Kinkel, J. F. M.; Tomlinson, E.; Smit, P. Thermodynamics and Extrathermodynamics of Organic Solute Liquid-Liquid Distribution between Water and 2,2,4-Trimethylpentane. Int. J. Pharm. 1981, 9, 121-36.

(6) Braxton, B. K.; Rytting, J. H. Solubilities and Solution Thermodynamics of Several Substituted Melamines. Thermochim. Acta 1989, 154, 27-47.

(7) Jouyban, A.; Acree, W. E., Jr. Solubility Prediction in Non-Aqueous Binary Solvents Using a Combination of Jouyban-Acree and Abraham Models. Fluid Phase Equilib. 2006, 249, 24-32.

(8) Acree, W. E., Jr. Mathematical representation of thermodynamic properties. Part 2. Derivation of the combined nearly ideal binary solvent (NIBS)/Redlich-Kister mathematical representation from a twobody and three-body interactional mixing model. Themochim. Acta 1992, 198, 71-79.

(9) Acree, W. E., Jr.; Abraham, M. H. Solubility Predictions for Crystalline Nonelectrolyte Solutes Dissolved in Organic Solvents Based Upon the Abraham General Solvation Model. Can. J. Chem. 2001, 79, 14661476.

(10) Stovall, D. M.; Acree, W. E., Jr.; Abraham, M. H. Solubility of 9-Fluorenone, Thianthrene and Xanthene in Organic Solvents. Fluid Phase Equilib. 2005, 232, 113-121.

Received for review January 15, 2008. Accepted February 1, 2008. The authors would like to thank the Drug Applied Research Center for the financial support under grant No. 85-83.

JE8000415 